\title{
FATORES QUE AFETAM A GERMINAÇÃO E A EMERGÊNCIA DE Xanthium strumarium L.: DORMÊNCIA, QUALIDADE DA LUZ E PROFUNDIDADE DE SEMEADURA ${ }^{1}$
}

\author{
ROBERTO E.B. TOLEDO ${ }^{2}$, MARCOS A. KUVA ${ }^{2}$ e PEDRO L.C.A. ALVES ${ }^{3}$
}

\begin{abstract}
RESUMO
Foram conduzidos três ensaios com o objetivo de estudar os efeitos de diferentes métodos de quebra de dormência das sementes, da qualidade da luz e da profundidade de semeadura na germinação e emergência do Xanthium strumarium L.(carrapichão). No primeiro ensaio, sob condições de câmara de crescimento, os tratamentos constaram de 5 métodos de quebra de dormência: mecânico (lixa), químico $\left(\mathrm{H}_{2} \mathrm{SO}_{4}\right.$ conc. por 10 min.), pré-tratamento em água (imersão por 2 horas), físico (choque térmico: água à $80^{\circ} \mathrm{C}$ por $2 \mathrm{~min}$.) e testemunha, que proporcionaram $100 \%, 93 \%, 93 \%, 87 \%$ e $80 \%$ de germinação, respectivamente, sem haver diferença estatística entre os mesmos. O pré-tratamento em água apresentou menor índice de velocidade de germinação (IVG) e os de mais não diferiram significativamente entre si. No segundo ensaio, também sob condições de câmara de cresci-

mento, os tratamentos de qualidade da luz constaram de 6 filtros de luz, que resultaram nas seguintes porcentagens de ger minação: azul- com refletividade máxima a $450 \mathrm{~nm}$ (13\%), verde-500 nm (33\%), vermelho-700 nm (13\%), vermelho/distante-760 nm (7\%), ausência de luz (26\%) e transparente - sem absortividade na região de 380 a $760 \mathrm{~nm}$ (testemunha, 73\%), indicando sensibilidade das sementes à qualidade de luz. No terceiro ensaio, sob condições de casade-vegetação, os tratamentos foram diferentes profundidades de semeadura ( 0 a $20 \mathrm{~cm}$, em intervalos de $2 \mathrm{~cm}$ ), sendo que o máximo de emergência ocorreu no intervalo de 0 a $8 \mathrm{~cm}$, no qual foi observado $67 \%$ de emergência do carrapichão, com maior índice de velocid ade emergência (IVE), sendo que após os $16 \mathrm{~cm}$, praticamente não houve emergência.
\end{abstract}

Palavras-chave: Carrapichão, fisiologia.

\section{ABSTRACT \\ Factors affecting germinat ion and emergence of Xanthiu m strumarium L.: Dormancy, light quality and sowing depth}

Three trials were carried out to study the effects of different methods to overcome dormancy, light quality and sowing depth on the germination and emergence of Xanthium strumarium L. (cocklebur). In the first trial, under growth chamber conditions, the treatments consisted of 5 methods of seed scarification: mechanical (sand-paper), chemical (concentrated sulphuric acid for $10 \mathrm{~min}$ ), sowing

\footnotetext{
1 Recebido para publicação em 28/02/93 e na forma revisada em 18/08/93.

2 Estagiários do Departamento de Biologia Aplicada à Agropecuária da FCAVJ/UNESP.

$3 \mathrm{Eng}^{\circ} \mathrm{Agr}^{\circ}$, MSC., Professor do Departamento de Biologia Aplicada à Agropecuária da FCAVJ/UNESP. Rodovia Carlos Tonani Km 5, CEP 14870-000, Jaboticabal, SP.
}

treatment ( 2 hours soaking in water ), physical (thermal shock: 2 min in water at $80^{\circ} \mathrm{C}$ ) and the control, which resulted in germination percentages of $100 \%, 93 \%, 93 \%, 87 \%$ and $80 \%$, respectively, without significant differences between the treatments; the sowing treatment caused lower germination speed (IVG). In the second trial, under identical conditions, the light quality treatment consisted of 6 light filters, resulting in the following germination percentages: blue - $450 \mathrm{~nm}(13 \%)$, green - $500 \mathrm{~nm} \mathrm{(33 \% ),} \mathrm{red} \mathrm{-} 700 \mathrm{~nm}$ (13\%), distant red - $760 \mathrm{~nm}(7 \%)$, darkness (26\%) and transparency - without absortion at 380 to $760 \mathrm{~nm}$ (control, 73\%), indicating that this species can be considered a preferencial photoblastic. In the third trial, under greenhouse conditions, 
the treatments comprised various sowing depths $(0$ to $20 \mathrm{~cm}$, at $2 \mathrm{~cm}$ intervals), with maximum emergence at 0 to $8 \mathrm{~cm}$ depth, with $80 \%$ of cocklebur emergence and higher speed

\section{INTRODUÇÃO}

Xanthium strumarium L. (carrapichão) tem sido relatado como planta daninha em 11 culturas em 28 países, mas sem se constituir como séria ou principal planta daninha nestas culturas. No Brasil, o carrapichão é uma planta comum em pastagem e vem se tornando um problema sério na cultura da soja, principalmente nas regiões Sul e CentroOeste, sendo também planta tóxica a equiínos e suínos (Lorenzi, 1991). A competição imposta pelo carrapichão manifesta-se principalmente por água e luz, visto ser esta uma planta que explora grande volume de solo e atinge uma altura elevada (Regner \& Stoller, 1989).

O carrapichão é uma planta anual da família Asteraceae (Compositae), com reprodução por sementes e com ciclo de 150 - 180 dias. O seu fruto (aquênio) é revestido por um envoltório (antocarpo) elíptico, de seção transversal-circular, fibroso, muito resistente, castanho-escuro, com aproximadamente $25 \mathrm{~mm}$ de comprimento por $8 \mathrm{~mm}$ em sua maior largura e provido de numerosas cerdas rijas e de ápice recurvada em forma de gancho, sendo duas apicais mais grossas e cônicas, bem distintas das demais (Holm et al., 1991; Lorenzi, 1991). Aquênio em número de dois por antocarpo, um dito "superior", profundamente dormente e outro "inferior", com menor dormência, germinando, portanto, em épocas diferentes. O aquênio "inferior" pode germinar de imediato ou dentro de poucos meses após a maturidade, enquanto o "superior" pode não germinar por vários meses ou mesmo anos (Holm et al., 1991; Lorenzi, 1991).

Deve-se entender por dormência a incapacidade de germinação de uma semente viável sob condições favoráveis de crescimento da plântula (Amen, 1968; Wareing \& Foda, 1957). Devido à dormência, as sementes de plantas daninhas podem persistir em solos por muitos anos e germinam uma vez que a dormência se rompa e as condições sejam favoráveis para o crescimento da plântula (Kogan, 1992).

A luz tem sido reconhecida como um requerimento para a germinação de sementes de muitas espécies de plantas daninhas (Black, 1969). A maioria dos solos atenuam a luz de uma forma muito efetiva e, dessa forma, a luz necessária para induzira germinação está presente apenas nos primeiros milímetros da superfície do solo. Além disto, a cobertura vegetal afeta a qualidade da luz, agindo como um filtro (Kogan, 1992).

A profundidade na qual a semente se encontra no solo é outro fator importante que vai influenciar na sua germinação e emergência. $O$ solo, além de constituir uma barreira à penetração da luz, exerce também um efeito de impedimento físico ao crescimento da plântula até que esta atinja a superfície do solo e deixe de depender das reservas dos cotilédones. Além disto, o conhecimento da profundidade na qual a plântula é capaz de emergir permite a adoção de práticas de manejo pertinentes, como, por exemplo, o empre- emergence index (IVE); no emergence was observed below $16 \mathrm{~cm}$.

Additional index words: Cocklebur, physiology.

go de métodos mecânicos (grades, cultivadores, etc.), associados ou não a métodos químicos (herbicidas).

Dessa forma, o objetivo deste trabalho foi estudar os efeitos de diferentes métodos de quebra de dormência, da qualidade da luz e a profundidade de semeadura sobre a germinação e a emergência do Xanthium strumarium L.

\section{MATERIAL E MÉTODOS}

O presente trabalho foi composto por duas etapas, sendo a primeira sobre métodos de quebra de dormência e de qualidade de luz, conduzidos sob condições de câmara de crescimento, e a segunda, em casa-de-vegetação, sobre profundidade de semeadura.

Em câmara de crescimento foram colocadas para germinar, sobre papel de filtro acondicionado em caixas plásticas (gerbox), 5 frutos de carrapichão (Xanthium strumarium L.), coletados no distrito de Luzitânia, município de Jaboticabal - SP, previamente selecionados quanto ao tamanho $(2,5$ $\mathrm{cm}$ de comprimento com $0,5 \mathrm{~cm}$ de diâmetro) e cor (parda sem manchas escuras). Os gerbox com as sementes acondicionadas foram umedecidos e mantidos sob condições controladas de intensidade luminosa $\left(108 \mu \mathrm{Em}^{-2} \mathrm{~s}^{-1}\right)$, fotoperíodo (14 horas) e temperatura $\left(25^{\circ} \mathrm{C} \pm 1\right)$.

No $1^{\circ}$ ensaio, os tratamentos constaram de cinco métodos de quebra de dormência e, baseado no melhor tratamento obtido neste ensaio, seis comprimentos de onda (qualidade de luz) foram testados no $2^{\circ}$ ensaio.

\section{Ensaio sobre métodos de quebra de dormência:}

1. Escarificação mecânica (utilização de lixa d'água, rompendo o revestimento dos frutos, antocarpos, até a exposição dos aquênios);

2. Escarificação química (embebição dos frutos revestidos em ácido sulfúrico concentrado por 10 minutos, sendo posteriormente lavados em água corrente);

3. Escarificação física (choque térmico: embebição dos frutos revestidos em água à $80^{\circ} \mathrm{C}$ por $2 \mathrm{mi}$ nutos);

4. Pré-tratamento em água (imersão dos frutos revesti dos em água destilada por 2 horas);

5. Testemunha.

\section{Ensaio sobre eficiência dos comprimentos de onda} (qualidade da luz):

1. Filtro de luz azul, com reflexão máxima a $450 \mathrm{~nm}$;

2. Filtro de luz verde, com reflexão máxíma a $500 \mathrm{~nm}$;

3. Filtro de luz vermelha, com reflexão máxima a 700 $\mathrm{nm}$;

4. Filtro de luz vermelho-distante, com reflexão máxima a $760 \mathrm{~nm}$;

5. Papel aluminado (ausência de luz); 
6. Filtro transparente de luz branca (testemunha), praticamente sem reflexão na região do visível, ou seja, com transmissividade de $\lambda$ na região de 380 a $760 \mathrm{~nm}$.

Estes filtros foram constituídos de papel celofane de cor correspondente ao tratamento, adotando-se para a testemunha o transparente (luz branca), revestindo-se hermeticamente as caixas plásticas (gerbox).

No terceiro ensaio, sob condições de casa-de-vegetação, o substrato (Latossolo Vermelho - Escuro, peneirado em tamis de $5 \mathrm{~mm}$ ) foi acondicionado em tubos de PVC de 10" com capacidade para 51 , nos quais foram colocados para germinar a diferentes profundidades (de 0 a $20 \mathrm{~cm}$, em intervalos de $2 \mathrm{~cm}$ ), 10 frutos de carrapichão previamente selecionados (quanto ao tamanho e cor) e escarificados (por escarificação mecânica). Os substratos foram umedecidos, procurando-se manter sua umidade mediante irrigações periódicas.

Para demarcação das diferentes profundidades de semeadura foram utilizadas estacas de bambu de $25 \mathrm{~cm}$, as quais foram marcadas em intervalos de $2 \mathrm{~cm}$, segundo metodologia de Velini (Velini et al., 1991).

O delineamento experimental utilizado em todos os ensaios foi o inteiramente casualizado com 3 repetições. Os dados obtidos foram submetidos à análise de variância pelo Teste $\mathrm{F}$ e as médias comparadas pelo teste de Tukey a 5\% de probabilidade, sendo que os dados relativos à porcentagem foram previamente transformados para arc ser \%. Os resultados relativos à profundídade de semeadura também foram submetidos a análise de regressão linear.

Ao término do período experimental, ou seja, 20 dias para os ensaios referentes à quebra de dormência e qualidade da luz, e 14 dias para o ensaio de profundidade de semeadura, avaliaram-se a porcentagem de germinação $(\% \mathrm{G})$ ou de emergência (\%E) e o índice de velocidade de germinação (IVG) ou de emergência (IVE), segundo fórmula de Pande et al. (1986), considerando-se como plântulas germinadas as que apresentaram comprimento de radícula superior a $2 \mathrm{~mm}$.

\section{RESULTADOS E DISCUSSÃO}

Observou-se no ensaio de quebra de dormência que, embora não se tenha constatado diferenças significativas entre os tratamentos (Tabela 1), a escarificação mecânica proporcionou tendência de aumento na porcentagem de germinação de 80 para $100 \%$, quando comparada à testemunha, seguida do pré-tratamento em água (semeadura), escarificação química e física, com 93, 93 e $87 \%$ de germinação, respectivamente. As sementes dos frutos que sofreram escarificação mecânica germinaram mais rápido do que àquelas que foram simplesmente imersas em água (tratamento de semeadura), sendo que ambos os tratamentos não diferenciaram da testemunha e dos demais tratamentos.

Segundo Kogan (1992), em muitos casos, a dormência se deve ao tegumento que pode impedira germinação devido a fatores como: bloqueio da entrada de água e luz para o embrião, limitação do intercâmbio gasoso, limitação física da expansão do embrião e restrição da remoção de inibidores químicos. No caso do Xanthium pensylvanicum, Porther \&
TABELA 1 - Valores médios de porcentagem e índice de velocidade de germinação (IVG) referentes aos métodos de quebra de dormência.

\begin{tabular}{|c|c|c|c|}
\hline \multirow{3}{*}{ Tratamentos } & \multicolumn{3}{|c|}{ Germinaçāo } \\
\hline & \multicolumn{2}{|c|}{ Porcentagem } & \multirow{2}{*}{ IVG } \\
\hline & $\begin{array}{c}\text { dados } \\
\text { orig. }\end{array}$ & $\begin{array}{c}\text { dados } \\
\text { transf. }\end{array}$ & \\
\hline Escarificação física & 87 & $72,0 \mathrm{a}^{2}$ & $20,7 \mathrm{ab}$ \\
\hline Escarificação mecânica & 100 & $89,3 \mathbf{a}$ & $28,0 \mathrm{ab}$ \\
\hline Escarificação química & 93 & 80,6 a & $22,3 \mathrm{ab}$ \\
\hline Pré - Tratamento em água & 93 & 80,6 a & $19,0 \mathrm{~b}$ \\
\hline Testemunha & 80 & 67,8 a & 29,7 a \\
\hline DMS & & 38,94 & 10,33 \\
\hline $\mathrm{F}$ & & $1,00 \mathrm{NS}$ & $4,41^{*}$ \\
\hline C.V.(\%) & & 18,57 & 16,07 \\
\hline
\end{tabular}

1 dados transformados em arc sen $\sqrt{\mathrm{x} / 100}$, para efeito de análise estatística.

2 valores seguidos de mesma letra năo diferem entre si pelo teste Tukey a 5\% de probabilidade.

- significativo ao nível de $5 \%$ de probabilidade pelo teste $\mathrm{F}$. NS não significativo.

Wareing (1974) concluíram que $\mathrm{O}_{2}$ se difunde igualmente bem através dos tegumentos das duas sementes dimórficas com diferentes níveis de dormência. Dessa forma, a semente dita "superior" não possui um maior grau de dormência devido a uma restrição diferencial à difusão do $0_{2}$ através do tegumento. Ent retanto, o reque rimento de $\mathrm{O}_{2}$ por esta semente é maior do que o da "inferior", apresentando melhor resposta ao aumento de concentração externa de 02 , o que torna o $0_{2}$ um fator requerido para quebrar a dormência em Xanthium pensylvanicum (Esashi et al., 1978).

$\mathrm{O}$ papel do $\mathrm{CO}_{2}$ como fator de regulação de dormência e de germinação não é bem conhecido. $\mathrm{O}$ aumento na germinação devido ao $\mathrm{CO}_{2}$ poderia ser atribuído a conseqüente produção de etileno (Katoh \& Esashi, 1975). 0 eixo embrionário de sementes não dormentes de Xanthium pensylvanicum é capaz de produzir mais etileno do que o de sementes dormentes, sendo que esta produção opera tanto aeróbica como anaerobicamente, enquanto que o embrião dormente perdeu a habilidade de produzir etileno aerobicamente (Esashi et al., 1972).

Wareing \& Foda (1957) postularam que os embriões dormentes de sementes superiores de Xanthium pensylvanicum contêm inibidores desconhecidos que não podem ser lixiviados através do tegumento impermeável. A incubação das sementes em altos níveis de $0_{2}$ resulta na destruição oxidativa dos inibidores, o que dá suporte à hipótese de inibidores no controle da dormência emXanthium. No entanto, resultados recentes com efeitos anaeróbicos na produção de etileno deixaram alguma dúvida sobre o papel de inibidores na dormência imposta pelo tegumento (Esashi et al., 1972). 
O estímulo da germinação de sementes de Xanthium por etileno, $0_{2}$ e temperaturas alternadas tem sido relacionado ao aumento da atividade na via respiratória secundária existente neste gênero (Esashi et al., 1982).

Dessa forma, a tendência de aumento na porcentagem de germinação (20\%) dos frutos que foram escarificados mecanicamente pode ser devido a um aumento na disponibilidade de $\mathrm{O}_{2}$ para as sementes, enquanto que a imersão do fruto em água (tratamento de semeadura) pode ter diminuído a disponibilidade de $\mathrm{O}_{2}$ em vírtude de a água se constituir em uma barreira à difusão deste gás, acarretando a diminuição na velocidade de germinação. Resultados semelhantes foram obtidos com escarificação mecânica de frutos de Bidens pilosa L. por Felippe \& Polo (1982) e Ocampo Ruiz et al. (1990).

Baseando-se nos resultados anteriores, procedeu-se à escarificação mecânica dos frutos do carrapichão, que posteriormente foram postos a germinar sob diferentes filtros de luz. Os resultados encontram-se expressos na Tabela 2. Observou-se que apesar de o filtro verde ter reduzido em mais de $50 \%$ a germinação, este não diferiu significativamente da testemunha (luz branca), sendo que os filtros azul, vermelho, vermelho-distante e ausência de luz não diferiram do filtro verde, mas reduziram significativamente a genninação do carrapichão quando comparados à testemunha.

TABELA 2 - Efeitos de diferentes filtros de luz na germinaçäo de sementes de Xanthium strumarium.

\begin{tabular}{|c|c|c|}
\hline \multirow{3}{*}{ Filtros } & \multicolumn{2}{|c|}{ Germinação } \\
\hline & \multicolumn{2}{|c|}{ Porcentagem } \\
\hline & dados orig. & dados transform. ${ }^{1}$ \\
\hline Transparente & 73 & $63,85 \mathrm{a}^{2}$ \\
\hline Azul & 13 & $21,14 b$ \\
\hline Vermelho & 13 & $21,14 b$ \\
\hline Vermelho-distante & 07 & $12,29 \mathrm{~b}$ \\
\hline Verde & 33 & $35,01 \mathrm{ab}$ \\
\hline Papel aluminado & 26 & $30,79 \mathrm{~b}$ \\
\hline DMS & & 31,21 \\
\hline $\mathrm{F}$ & & $7.59^{* *}$ \\
\hline C.V.(\%) & & 37,07 \\
\hline $\begin{array}{l}{ }^{1} \text { Dados originais foram } \\
\text { análise estatística. } \\
2 \text { Valores seguidos de me } \\
5 \% \text { de probabilidade. V } \\
\text { * Significativo ao nível }\end{array}$ & $\begin{array}{l}\text { ansformados em at } \\
\text { ma letra não difere } \\
\text { ores médios de } 3 \mathrm{r} \\
1 \% \text { de probabilida }\end{array}$ & $\begin{array}{l}\text { sen } \sqrt{\% / 100} \text { para efeito d } \\
\text { entre si pelo teste Tukey } \\
\text { petiçóes. } \\
\text { le pelo teste F. }\end{array}$ \\
\hline
\end{tabular}

A luz tem sido reconhecida como um requerimento para a germinação de sementes de muitas espécies de plantas daninhas. Estas sementes, em geral, são pequenas e contêm relativamente pouca reserva nutritiva e, com isso, a germina- ção sobre ou próxima à superfície do solo é necessária a sua sobrevivência. O requerimento de luz é a principal razão pela qual a germinação de sementes é restrita à proximidade da superfície do solo. Muitos solos atenuam efetivamente a luz. Dessa forma, luz suficiente para induzir a germinação está presente apenas nos primeiros milímetros da superfície do solo. Em solos agrícolas, muitas sementes são revolvidas pelo cultivo e podem germinar apenas quando re-expostas à luz no cultivo subseqüente (Kogan, 1992; Wolley \& Stoller, 1978).

Além disto, também num meio agrícola, a semente é exposta à luz por períodos prolongados, que apresenta preferencialmente uma composição espectral complexa. $\mathrm{O}$ sombreamento por vegetação, por exemplo, produz uma relação vermelho / vermelho-distante baixa, reduzindo ou inibindo a germinação de sementes de muitas espécies, que germinam rapidamente sob luz branca difusa, ou seja, aquelas que estão sujeitas à fitocromicidade (Gorski et al., 1978). Neste caso, a genninação é dependente do vermelho-distante e o tegumento das sementes de muitas espécies daninhas pode reduzir a efetividade deste comprimento de onda em induzir a germinação (Taylorson \& Hendricks, 1977).

No caso do Xanthium strumarium constatou-se que os comprimentos de onda testados, ou seja, a ausência deles proporcionada pelos filtros, todos reduziram a porcentagem de germinação, sem diferenças entre os mesmos. Segundo Klein \& Felippe (1991), embora estatísticamente o Xanthium strumarium possa ser considerada espécie fotoblástica positiva, este caráter é apenas quantitativo, uma vez que tanto na presença quanto na ausência de luz, ocorreu considerável germinação de suas sementes. Este comportamento pode ser considerado corno um fotoblastismo preferencial.

A porcentagem de emergência das plântulas cujas sementes se encontravam até $8 \mathrm{~cm}$ de profundidade foi praticamente constante (Tabela 3) e, através da análise de regressão, obteve-se para o intervalo $0-8 \mathrm{~cm}$ porcentagem de emergência igual a 71,2. No entanto, a emergência das plântulas cujas sementes se encontravam em profundidades superiores a 8 $\mathrm{cm}$ foi significativamente inferior àquelas que se encontravam até $8 \mathrm{~cm}$, demonstrando decréscimo linear, sendo que, pela equação obtida pela análise de regressão $(\% \mathrm{E}=67,29$ $3,49 \mathrm{P} ; \mathrm{R}=0,98 * *)$, a cada centímetro que se aumentava a profundidade de semeadura houve uma redução de 3,49 unidades na porcentagem máxima estimada $(67,29 \%)$. O mesmo comportamento foi verificado para o índice de velocidade de emergência, sendo que as plântulas oriundas de sementes que se encontravam até $8 \mathrm{~cm}$ de profundidade emergiram mais rapidamente que aquelas que se encontravam em profundidades superiores a $8 \mathrm{~cm}$, com decréscimo linear da velocidade com aumento da profundidade a partir de $8 \mathrm{~cm}$. A análise de regressão revelou velocidade constante de emergência até $8 \mathrm{~cm}(\mathrm{IVE}=190)$, após os quais o decréscimo foi linear (IVE $\left.=198-10,42 \mathrm{P} ; \mathrm{R}^{2}=0,96^{* *}\right)$, onde a cada centímetro em que se aumentava a profundidade de semeadura houve uma redução de 10,42 unidades no índice de velocidade máxima de emergência estimado (198).

Barbosa et al. (1991) verificaram que os níveis mais altos de porcentagem e índices de velocidade de emergência de plântulas do gênero Digitaria encontraram-se na superfície e a $2 \mathrm{~cm}$ de profundidade. Verificaram ainda que, de uma 
TABELA 3 - Valores médios de porcentagem $e$ índice de velocidade de emergência (IVE) referentes a diferentes profundidades de semeadura.

\begin{tabular}{|c|c|c|c|}
\hline \multirow{3}{*}{$\begin{array}{c}\text { Profundidades } \\
\text { (cm) }\end{array}$} & \multicolumn{3}{|c|}{ Emergência } \\
\hline & \multicolumn{2}{|c|}{ Porcentagem } & \multirow{2}{*}{ IVE } \\
\hline & dados orig. & dados transf. ${ }^{1}$ & \\
\hline 0 & 63 & $52,86 \mathrm{a}^{2}$ & $156,00 \mathrm{ab}$ \\
\hline 2 & 80 & 63,93 a & 239,33 a \\
\hline 4 & 73 & 59,00 a & 200,00 a \\
\hline 6 & 73 & 60,00 a & 199,33 a \\
\hline 8 & 67 & 54,78 a & $154,67 \mathrm{ab}$ \\
\hline 10 & 34 & $35,97 \mathrm{~b}$ & $97,23 \mathrm{bc}$ \\
\hline 12 & 25 & $30,33 \mathrm{bc}$ & 77,78 bcd \\
\hline 14 & 18 & $25,25 \mathrm{bc}$ & $44,44 \mathrm{~cd}$ \\
\hline 16 & 10 & $18,44 \mathrm{~cd}$ & $25,00 \mathrm{~cd}$ \\
\hline 18 & 3 & $9,45 \mathrm{de}$ & $3,00 \mathrm{~d}$ \\
\hline 20 & 0 & $0,00 \mathrm{e}$ & $0,00 \mathrm{~d}$ \\
\hline DMS & & 15,59 & 88,89 \\
\hline $\mathrm{F}$ & & $52,14^{* *}$ & $23,87^{* *}$ \\
\hline C.V. $(\%)$ & & 14,33 & 28,06 \\
\hline $\mathrm{R}^{2}$ & & $0,88^{* *}$ & $0,86^{* *}$ \\
\hline
\end{tabular}

${ }^{1}$ Os dados originais foram transformados $\mathrm{em}$ arc sen $\sqrt{\% / 100}$ para efeito de análise estatística.

2 Valores seguidos de mesma letra nấo diferem entre si pelo teste Tukey a 5\% de probabilidade.

** significativo ao nível de $1 \%$ de probabilidade pelo teste $\mathrm{F}$.

maneira geral, os valores de porcentagens e os índices de velocidade de emergência diminuem estatísticamente à medida que se aumenta a profundidade de semeadura.

Provavelmente os resultados mais expressivos de emergência das plântulas de carrapichão até $8 \mathrm{~cm}$ de profundidade estão relacionados coma maior intensidade luminosa, que promove a germinação das sementes, associada ao fato de que a barreira física imposta pelo solo à germinação e à emergência é menor. Por outro lado, a possibilidade de o carrapichão emergir ainda quando semeado a $8 \mathrm{~cm}$ de profundidade ou mais possibilita a esta planta uma sobrevivência maior em áreas com perturbações pelos tratos culturais, possibilitando futuras infestações.

\section{LITERATURA CITADA}

AMEN, R. D. A model of seed dormancy. Botanic Review, New York, 34 (1): 1-31, 1968.

BARBOSA, J. M.; SILVA, T.S.; ANDREANI JÚNIOR, R.; PITELLI, R.A. \& BARBOSA, L.M. Germinação e emergência de plântulas paratrés espécies de gramíneas invasoras de cultura do gênero Digitaria Heisler ex Haller. Acta Botânica Brasileira, São Paulo, 1 (3): 7-13, 1991.
BLACK, M. Light - controlled germination of seeds, Symp. Soc. Exp. Biol., 23, 193, 1969.

KATOH, H. \& ESASHI, Y. Dormancy and impotency of cocklebur seeds. II Phase sequence in germination process. Plant and Cell Physiology, 16: 697, 1975.

ESASHI, Y.; OHHARA, Y.; KODAKY, K. \& WATANABE, $\mathrm{K}$. Two $\mathrm{C} 2 \mathrm{H} 4$ - producing systems in cocklebur seeds. Planta, 50: 382, 1972.

ESASHI, Y.; TSUKADA, Y. \& OHHARA, Y. Interrelation between low temperature and anaerobiosis in the induction of germination of cockelebur seed. Australian Journal Plant Physiology, 5: 337, 1978.

ESASHI, Y.; NOBUYORI, I.; SAIJOH, K. \& SATOH, M. A biomodal germinathion response to temperature in cocklebur, seeds. II. ATP and andenylate pool, Plant Cell and Environment, 6: 55, 1982.

FELIPPE, G. M. \& POLO, M. Germinação de ervas invasoras: efeito de luz e escarificação. Revista Brasileira de Botânica, 6: 55, 1982.

GORSKI, T.; GORSKA, K. \& RYBYCKI, J. Studies on the germination of seeds under leaf canopy. Flora, 167: 289, 1978.

HOLM, L. G.; PANCHO, J.V.; HERBERGER, J.P. \& PLUCKNETT, D.L. The world's worst weeds - distribution and biology. 2 ed. Malabar, Flórida: Krieger Publishing Company, 609p., 1991.

KLEIN, A. \& FELIPPE, G. M. Efeito da luz na germinação de sementes de ervas invasoras. Pesquisa Agropecuária Brasileira, 26 (7): 955-966. 1991.

KOGAN, M. A. Malelzas; Ecofisiologia y estratégias de control. Santiago: Pontificia Universidad Catolica, 402p., 1992.

LORENZI, H. Plantas daninhas do Brasil; terrestres, aquáticas, parasitas, tóxicas e medicinais. 2. ed. Nova Odessa Plantarum, 1991. 440 p.

OCAMPO RUIZ, P. A.; MEDINA PITALÚA, J.L. \& DOMÍNGUES VALENZUELA, J.A. Influencia de la temperatura, luz, estratificación y escarificación mecânica sobre la germinaçión de cuatro espécies de malezas de importância agrícola en México. Chapingo 4 (2): 69, 1990.

PANDE, P. C.; DEBLISH, P.K. \& JAIN, D.K. (1980) apoud PUTNAM, A. R. \& TANG, C. S. The science of allelopathy. New York, John Wiley \& Sons, 1986. p. 136.

PORTHER, N. G. \& WAREING, P. F. The role the oxygen permeability of the seed coat in dormancy of seed Xanthium pensylvanicum Waller. Journal of Experimental Botany, 25: 583, 1974.

REGNER, E. E. \& STOLLER, W. S. The effects of soybean (Glycine max) interference on the canopy architectur of common cockleburXanthium strumarium), jimson weed (Datura strumarium), and velvet leaf (Abutilon theophrasti). Weed Science, 37: 187-195, 1989. 
TAYLORSON, R. B. \& HENDRICKS, S. B. Dormancy in seeds. Annual Review of Plant Physiology, 28: 331, 1977.

VELINI, E. D.; PIMENTA, F.A.; FREDERICO, L.A. \& PEREIRA, P.C.V. Determinação da profundidade de geminação de Brachiaria plantaginea e Cenchrus echinatus em condições de campo. In: Congresso Brasileiro de Herbicidas e Plantas Daninhas, XVIII, Brasília, 1991. Resumos, 14-15.
WAREING, P. F. Endogeneous inhibitors in seed germination and dormancy. In: Encyclopedia of Plant Physiology, 15 (2) 909-924, 1965.

WAREING, P. F. \& FODA, H. A. Growth inhibitors and dormancy in Xanthium seed. Plant Physiology, 10: 266, 1957.

WOLLEY, J. L. \& STOLLR, E. W. Light penetration and light - induced seed germination in soil. Plant Physiology, 61: 597, 1978. 